\title{
Video Article \\ Novel Production Protocol for Small-scale Manufacture of Probiotic Fermented Foods
}

\author{
Nieke Westerik ${ }^{1,2}$, Alex Paul Wacoo ${ }^{1,2,3}$, Wilbert Sybesma ${ }^{1}$, Remco Kort ${ }^{1,2,4,5}$ \\ ${ }^{1}$ Yoba for Life Foundation \\ ${ }^{2}$ Department of Molecular Cell Biology, Vrije Universiteit Amsterdam (VUA) \\ ${ }^{3}$ Uganda Industrial Research Institute (UIRI) \\ ${ }^{4}$ Micropia, Natura Artis Magistra \\ ${ }^{5}$ Department of Microbiology and Systems Biology, Netherlands Organisation for Applied Scientific Research (TNO)
}

Correspondence to: Remco Kort at remco.kort@tno.nl

URL: https://www.jove.com/video/54365

DOI: doi:10.3791/54365

Keywords: Microbiology, Issue 115, Fermented milk, pasteurization, incubation, fermentation, Lactobacillus rhamnosus yoba 2012, Streptococcus thermophilus C106, probiotic, starter culture

Date Published: 9/10/2016

Citation: Westerik, N., Wacoo, A.P., Sybesma, W., Kort, R. Novel Production Protocol for Small-scale Manufacture of Probiotic Fermented Foods. J. Vis. Exp. (115), e54365, doi:10.3791/54365 (2016).

\section{Abstract}

A novel dried bacterial consortium of Lactobacillus rhamnosus yoba 2012 and Streptococcus thermophilus C106 is cultured in $1 \mathrm{~L}$ of milk. This fresh starter can be used for the production of fermented milk and other fermented foods either at home or at small-scale in rural settings. For the fresh starter, $1 \mathrm{~L}$ of milk is pasteurized in a pan that fits into a larger pan containing water, placed on a source of heat. In this water bath, the milk is heated and incubated at $85^{\circ} \mathrm{C}$ for $30 \mathrm{~min}$. Thereafter, the milk is cooled down to $45^{\circ} \mathrm{C}$, transferred to a vacuum flask, inoculated with the dried bacteria and left for at least $16 \mathrm{hr}$ between $30^{\circ} \mathrm{C}$ and $45^{\circ} \mathrm{C}$. For the purpose of frequent home production, the fresh starter is frozen into ice cubes, which can be used for the production of small volumes of up to $2 \mathrm{~L}$ of fermented milk. For the purpose of small-scale production in resource-poor countries, pasteurization of up to $100 \mathrm{~L}$ of milk is conducted in milk cans that are placed in a large sauce pan filled with water and heated on a fire at $85^{\circ} \mathrm{C}$ for $30 \mathrm{~min}$, and subsequently cooled to $45^{\circ} \mathrm{C}$. Next, the $100 \mathrm{~L}$ batch is inoculated with the $1 \mathrm{~L}$ freshly prepared starter mentioned before. To assure an effective fermentation at a temperature between 30 and $45^{\circ} \mathrm{C}$, the milk can is covered with a blanket for $12 \mathrm{hr}$. For the production of non-dairy fermented foods, the fresh starter is left in a cheese cloth for $12 \mathrm{hr}$, and the drained-off whey can be subsequently used for the inoculation of a wide range of food raw materials, including vegetables and cereal-based foods.

\section{Video Link}

The video component of this article can be found at https://www.jove.com/video/54365/

\section{Introduction}

This article describes a production protocol that enables the production of nutritious and probiotic fermented milk and other probiotic fermented foods with the help of a seed culture that has proven health benefits. The protocol is robust and easy to execute by anyone at any place, including resource-poor countries.

In Sub-Saharan Africa, $21 \%$ of the deaths of children $<5$ years is caused by diarrhea ${ }^{1}$, of which $29 \%$ is caused by rotaviral etiology in particular ${ }^{2}$. It has been shown that daily consumption of fermented food containing a recommended dose of $1 \times 10^{10} \mathrm{CFU}$ of $L$. rhamnosus GG stimulates gut health and reduces the incidence and severity of rotavirus-associated diarrhea ${ }^{3-7}$.

Beneficial bacteria are present in wide range of traditional fermented foods all over sub-Saharan Africa ${ }^{8-10}$. However, these foods are almost exclusively home-produced, have a relative short shelf life and have increased safety risks due to the uncontrolled nature of the fermentation ${ }^{11}$. Furthermore, the consumption of these traditional foods declines due to urbanization and a general westernization of diets in Africa ${ }^{10,12}$.

The generic probiotic bacterium $L$. rhamnosus yoba $2012^{13}$, which is identical to $L$. rhamnosus $G G$, was introduced after the original patent for $L$. rhamnosus GG had expired ${ }^{14}$. The dried seed culture has an $A_{w}$ of approximately 0.1 , which keeps the viability high after a storage period of at least one year at room temperature (data not shown).

The seed culture is packaged in portions of $1 \mathrm{~g}$ and can be used for the production of a maximum of $100 \mathrm{~L}$ fermented milk. When producing one or two batches a day, the starter cultures can help to reach a production capacity of up to 1,000 L per week from every-day fresh milk.

The use of L. rhamnosus yoba 2012 with $S$. thermophilus $C 106$ as an adjuvant culture that allows the probiotic Lactobacillus to propagate ${ }^{15}$ is a unique bacterial consortium that has not been reported by other authors. The production protocol involves resuspension of the content one package $(1 \mathrm{~g})$ of freeze dried starter culture (seed culture) in $1 \mathrm{~L}$ of milk, resulting in a so-called fresh starter after incubation for a period of $16 \mathrm{hr}$. The fresh starter is subsequently used to inoculate a maximum of $100 \mathrm{~L}$ of milk. This method of pre-incubation reduces the amount of 
freeze dried bacteria used, thereby reducing the costs of production in comparison to direct incubation as for example described by Goff ${ }^{16}$. The formulation used for the protocol described in this paper maintains the advantages of a freeze dried culture, such as shelf life stability and easy storage and handling, resulting in highly reproducible fermentations.

Furthermore, the production protocol as described in this article does not require high-tech equipment as opposed to the standard production methods used in the developed world ${ }^{17}$.

Finally the fresh starter can be used for the inoculation of other (non-dairy) raw materials for the production of a wide range of fermented foods as is successfully shown for Obushera, Kwete, Uji, and Zomkom, all cereal-based traditionally fermented foods from Uganda (the first two), Kenya and Burkina Faso, respectively ${ }^{15}$. This is only a minor fraction of the vast amount of fermented foods developed in Africa ${ }^{18}$.

Fermentation is the breakdown of macromolecules such as starch, sugars and proteins into products that have an increased digestibility, through the activities of enzymes and/or microorganisms. Fermentation is a widely used technique in Sub-Saharan Africa. Together with drying and salting it enables food preservation in the absence of cooling facilities or industrial techniques such as canning ${ }^{9,19}$. Traditional fermentation often uses back-slopping, in which a small portion from a previous batch is added to a new batch to facilitate the fermentation and to reduce the chance of fermentation failure ${ }^{11}$. Harrison and Tomkins ${ }^{20}$ describe a wide range of traditional African fermented foods based on maize, sorghum or millet, and the beneficial role these foods can bring to weaning children, for instance by reducing childhood diarrhea and associated mortality. Nout and Sarkar ${ }^{19}$ describe the traditional production of a fermented cassava dish that is widely consumed in western Africa. Franz et al. ${ }^{9}$ provide an extensive description of African fermented foods categorized in cereal and vegetable foods, starchy root crop foods and animal protein foods. In addition to that, Narvhus and Gadaga ${ }^{21}$ specifically describe the traditional production of fermented milk in Africa.

For the production of probiotic fermented milk (or other fermented foods) especially in the case of home production, the availability of a freezer is advantageous to store the fresh starter in frozen portions. At resource-poor countries, the production of fermented milk can be executed well by milk-producing communities. Current experience with local communities in Uganda indicates that Dairy Cooperatives are suitable entities to take up yogurt production from their own milk supplies. The availability of a milk can is advantageous, although it is also possible, though less preferable, to prepare large batches of fermented milk in a larger pan. Furthermore, the availability of electrical power and the therewith connected presence of cooling facilities in local shops and kiosks in resource-poor countries is an advantage in the expansion of the business and the reduction of losses due to spoilage. However, as will be discussed in the protocol, through the addition of potassium sorbate it is possible to preserve the yogurt for several days at ambient temperature and reduce spoilages in the event of power fluctuations.

\section{Protocol}

\section{Preparation of Fresh Starter}

To prepare the fresh starter, take $1 \mathrm{~L}$ of either Ultra-high-temperature (UHT) processed milk or fresh cow's milk. If it is UHT milk, proceed to step 1.3. If it is fresh cow's milk, proceed with step 1.1.

1. Milk testing for fresh cow's milk

1. For the organoleptic test to detect abnormalities or spoilage of the milk, check the visual appearance of the milk and check its smell.

2. For the cloth-on-boiling test, transfer a small sample of the milk to a tablespoon. Hold the spoon above a source of heat until the milk starts to boil. Remove the spoon from the source of heat and look at the milk to detect signs of clotting that indicate bad quality milk.

3. For the lactometer test, fill a cylinder, beaker glass or any other hollow object at least $15 \mathrm{~cm}$ high with milk. Place the lactometer in the milk. Lactometer readings of 28 or more for milk at $30{ }^{\circ} \mathrm{C}$ indicate milk of sufficient density without added water.

4. For the ethanol test, make an $80 \%$ ethanol solution in distilled water. Mix an equal amount of milk with an equal amount of $80 \%$ ethanol, for example by mixing a teaspoon of milk with a teaspoon of $80 \%$ ethanol in a cup. Look at the mixture to detect signs of clotting that indicate bad quality milk.

2. When fresh milk is being used, filter the milk with a sieve or filter cloth (pore size $0.1-0.5 \mathrm{~mm}$ ), previously pasteurized in boiling water for 15 $\min$.

3. Pasteurization

1. Transfer the milk into a small pan and close the pan with a lid. Place the pan in a slightly larger pan. Fill the larger pan with water, up to $2 \mathrm{~cm}$ below the rim of the smaller pan.

2. Heat this set up using an appropriate source of heat (e.g., electrical heating, gas burner, charcoal stove, wood fire) until the milk reaches $85^{\circ} \mathrm{C}$, as measured with a laboratory thermometer.

3. Turn the source of heat to low and maintain the temperature of $85^{\circ} \mathrm{C}$ for $30 \mathrm{~min}$.

4. Remove the pan with the milk from the pan with the water and let it cool. Optionally transfer the pan to a pan with cold water to speed up the cooling process. Do not remove the lid from the pan, except for taking temperature measurements.

5. Let the milk cool down to $45^{\circ} \mathrm{C}$, as measured with a laboratory or kitchen thermometer. At this point, transfer the milk to a vacuum flask, and inoculate the milk by adding the content of a packet of the seed culture $(1 \mathrm{~g})$.

6. Leave the inoculated milk for $16 \mathrm{hr}$ in the vacuum flask to allow fermentation to take place. Check the final pH of the fermented milk, which should be 4.4 or less, as measured with a $\mathrm{pH}$ meter or $\mathrm{pH}$ paper.

7. After fermentation, stir or shake the product for approximately 5 - $10 \mathrm{~min}$ to obtain a smooth texture.

8. Store until the next steps.

1. For home production, pour the fresh starter into an ice cube tray to make ice cubes of $10 \mathrm{ml}$. Place the ice cubes in the deep freezer $\left(-18^{\circ} \mathrm{C}\right)$ and proceed with section 2 within 3 months.

2. For production up to $100 \mathrm{~L}$ scale in resource poor settings, proceed with section 3 , thereby assuring that step 3.5 is started $16 \mathrm{hr}$ after completion of step 1.5. Alternatively, place the fresh starter in the fridge $\left(7^{\circ} \mathrm{C}\right)$ after step 1.6 and proceed with section 3 within 5 days. 
3. For the production of a wide range of non-dairy type of fermented foods, proceed with section 4 .

\section{Production of Small Batches at Household Level}

1. Use any convenient amount of milk (suggested 1-10 L).

2. Perform step 1.1.

3. Perform step 1.2.

4. Pasteurization

1. Transfer the milk into a small pan and close the pan with a lid. Place the pan in a slightly larger pan. Fill the larger pan with water, up to $2 \mathrm{~cm}$ below the rim of the smaller pan.

2. Heat this set up using an appropriate source of heat (e.g., electrical heating, gas burner, charcoal stove, wood fire) until the milk reaches $60{ }^{\circ} \mathrm{C}$, as measured with a laboratory or kitchen thermometer.

3. Optional: At this point add sugar at a suggested concentration of $5 \%(\mathrm{w} / \mathrm{v})$, as measured with a balance. Stir well with a mixing spoon previously pasteurized by submerging in boiling water for $15 \mathrm{~min}$. Continue heating until the milk reaches $85^{\circ} \mathrm{C}$, as measured with a laboratory or kitchen thermometer.

4. Turn the source of heat to low and maintain the temperature of $85^{\circ} \mathrm{C}$ for $30 \mathrm{~min}$.

5. Perform step 1.4 .

6. Let the milk cool down to $45^{\circ} \mathrm{C}$, as measured with a laboratory or kitchen thermometer. At this point, inoculate the milk by adding one ice cube (as was prepared under section 1) for each liter of milk and transfer the milk to (a) vacuum flask(s).

7. Leave the inoculated milk in the vacuum flask to allow fermentation to take place until a pH of 4.4 is reached as measured with a pH meter or $\mathrm{pH}$ paper. This is estimated to take $12 \mathrm{hr}$.

8. Perform step 1.7.

9. Transfer the fermented milk to a fridge $\left(7^{\circ} \mathrm{C}\right)$ and let it cool for at least $3 \mathrm{hr}$ before consumption. When stored under proper refrigeration, the product is best consumed within one month.

\section{Production in Rural Setting in Resource-poor Countries}

Note: Use a maximum of $100 \mathrm{~L}$ of milk per $1 \mathrm{~L}$ fresh starter.

1. Perform step 1.1

2. Perform step 1.2

3. Pasteurization:

1. Transfer the milk into a milk can of suitable size and close the can with a lid. Place the can in a large pan. Fill the pan with water, up to the highest level possible.

2. Heat this set-up using an appropriate source of heat (wood fire is the fastest and often the most cost-effective) until the milk reaches 60 ${ }^{\circ} \mathrm{C}$, as measured with a laboratory or kitchen thermometer.

3. Optional: Depending on taste preference, add sugar in a ratio of $50 \mathrm{~g}$ per liter. Stir well with a mixing spoon that was previously pasteurized by submerging in boiling water for $15 \mathrm{~min}$. Continue heating until the milk reaches $85^{\circ} \mathrm{C}$, as measured with a laboratory or kitchen thermometer.

4. Reduce the heat and maintain the temperature of $85^{\circ} \mathrm{C}$ for $30 \mathrm{~min}$.

4. Remove the can with the milk from the pan with the water and let it cool. To speed up the cooling process, transfer the can to a pan with cold water. Do not remove the lid from the can, except for measuring the temperature.

5. Let the milk cool down to $45^{\circ} \mathrm{C}$, as measured with a laboratory or kitchen thermometer. Remove the can from the cold water pan. At this point, inoculate the milk by adding the complete fresh starter (this can never be overdosed).

6. Wrap a blanket around the milk can for the purpose of isolation and the prevention of a rapid decrease in temperature (ideally, the temperature will remain between 45 and $35^{\circ} \mathrm{C}$ ). Leave the inoculated milk in the can to allow fermentation to occur until a pH of 4.4 is reached. This process takes approximately $12 \mathrm{hr}$.

7. Remove the blanket from the can and open the can.

1. Optional: Remove the watery top layer of the fermented milk to obtain a smoother texture of the probiotic fermented milk (yogurt).

2. Optional: Add food-grade artificial flavors (e.g., strawberry or vanilla), for instance at a concentration of $0.1 \%$ ( $/ \mathrm{v}$ ) dosed by a $10 \mathrm{ml}$ measuring cup or spoon (depending on the concentration of the flavor and the preference of the customer).

3. Optional: Add preservatives. A cost effective and safe choice is the use of potassium sorbate at a maximum concentration of $0.12 \mathrm{~g} / \mathrm{L}$ (source: http://www.efsa.europa.eu/en/efsajournal/pub/4144 advises $3 \mathrm{mg} / \mathrm{kg}$ bw/day).

Note: Young children with a weight below $10 \mathrm{~kg}$ should take not more than a maximum of $30 \mathrm{mg}$ potassium sorbate when taking a dose of $250 \mathrm{ml}$ fermented milk, which is corresponds to a dosage of approximately 2 tablespoons per $50 \mathrm{~L}$.

4. Stir the fermented milk thoroughly with a metal spoon that was previously sterilized by submerging in boiling water for 15 min.

8. Optional: Pack the fermented milk, transfer to a fridge $\left(7^{\circ} \mathrm{C}\right)$ and cool for at least $3 \mathrm{hr}$ before consumption.

Note: When stored under proper refrigeration, below $7^{\circ} \mathrm{C}$, the product is best consumed within two weeks. When stored under proper refrigeration, and preservative is added as described under 3.7 .3 the product is best consumed within 4 weeks.

\section{Production of Other Fermented Foods}

This section describes the production of fermented foods other than fermented milk with a maximum volume of approximately $50 \mathrm{~L}$. 
1. Pasteurize a cheesecloth by submerging in boiling water for at least $15 \mathrm{~min}$. Tie the cheese cloth loosely over a bowl or pan that can hold approximately $2 \mathrm{~L}$ by using a rope or a rubber band.

2. Pour the fresh starter on the cheese cloth, avoid spilling over, and keep enough space between the bottom of the bowl and the cheesecloth.

3. Place the bowl in a fridge at approximately $7{ }^{\circ} \mathrm{C}$ for $8-12 \mathrm{hr}$ until approximately $0.5 \mathrm{~L}$ of whey has drained from the yogurt into the bowl.

4. Use the whey to make different types of fermented foods. Examples are given below.

Note: The obtained fermented foods will contain whey (milk). Milk and its derivatives are recognized among the most common ingredients causing food allergies and intolerances.

1. For the production of Obushera, a sorghum or millet based Ugandan beverage follow the protocol described by Mukisa et al. ${ }^{22}$.

2. For the production of $\mathrm{Uji}$, a Kenyan porridge made from maize or sorghum or a mixture of both, follow the protocol used by the Jomo Kenyatta University of Agriculture and Technology in Kenya and described by Kort et al. ${ }^{15}$.

3. For the production of Zomkom, a sorghum-based beverage from Burkina Faso, follow the protocol described by Christèle et al. ${ }^{23}$ and Kort et al. ${ }^{15}$.

4. For the production of Mutandabota, a product from the fruits of the baobab tree and milk that is widely consumed in southern Africa follow the procedure described by Mpofu et al. ${ }^{24}$. Note that for this product the fresh starter that is obtained in section 1 can be used directly without first performing step $4.1-4.3$.

\section{Representative Results}

The left side of Table 1 shows a schematic diagram of section 1 of the protocol. This is followed by a generalized combined diagram of sections 2 and 3 on the right side of the table.

Fermentation profiles of milk inoculated with the seed culture using the production protocol as described in this article were recorded. Figure 1 shows the fermentation of the fresh starter (as described in section 1). Figure 2 shows the fermentation of the fermented milk (end product, as described in sections 2 and 3 ). Since in practice in rural areas strict temperature control is difficult, measurements were made at temperature of $37^{\circ} \mathrm{C}$ and $45^{\circ} \mathrm{C}$

For fermentation at $37^{\circ} \mathrm{C}$, the acidification profiles of the two sachets tested show a slight difference in the onset of the exponential acidification of approximately 30 minutes, both in the production of the fresh starter and the end product. The final $\mathrm{pH}$ values of both cultures are identical after $16 \mathrm{hr}$.

Typical $\mathrm{pH}$ values and titers for the propagated $L$. rhamnosus and $S$. thermophilus strains following the described production procedures for different fermented foods can be found in Table 2. Cell counts for $L$. rhamnosus and S. thermophilus were determined on MRS agar medium and LM17, respectively, by using commonly applied microbiological plating methods. Final cell counts of $L$. rhamnosus yoba 2012 were $1.7 \mathrm{x}$

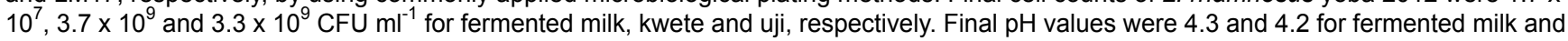
kwete, respectively. Preliminary results indicated that the addition of potassium sorbate prior to fermentation does not negatively influence but even increases the number of viable $L$. rhamnosus yoba 2012 bacteria in yogurt two weeks after production (data not shown).

Figure 3 shows the results of high-performance liquid chromatography (HPLC) in combination with a refractive index (RI) detector of nonfermented milk compared to the fermented milk. The results indicate that lactose levels in the milk decrease, while lactic acid levels and galactose levels increase, which is a result of the metabolic activity of the seed culture.

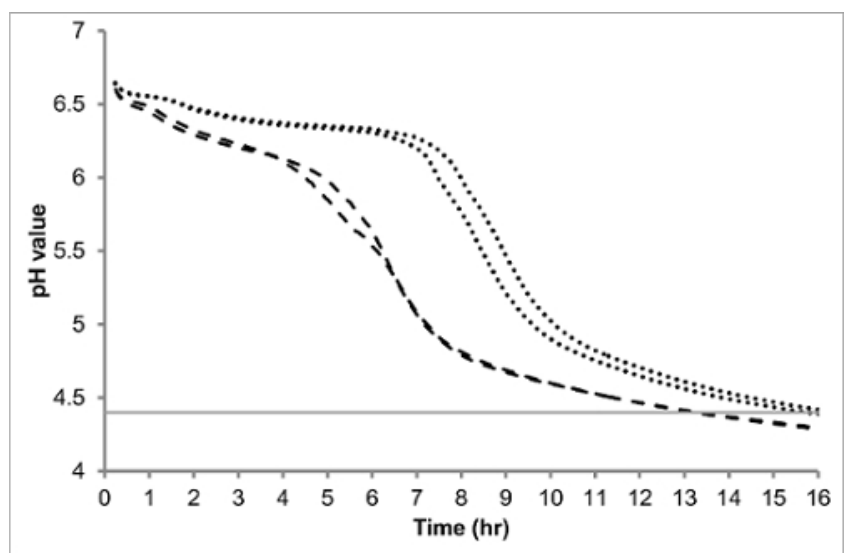

Figure 1. Fermentation profile of the fresh starter made of semi skimmed milk (1.5\% fat, 3.5\% protein). One liter of milk was inoculated with one sachet $(1 \mathrm{~g})$ of seed culture and fermented at $37^{\circ} \mathrm{C}\left(\cdots\right.$, , duplicate) as well as $45^{\circ} \mathrm{C}(----$, duplicate) for $16 \mathrm{hr}$. The straight line (----) at $\mathrm{pH} 4.4$ is inserted as an indication to determine when the fermentation is completed. Please click here to view a larger version of this figure. 


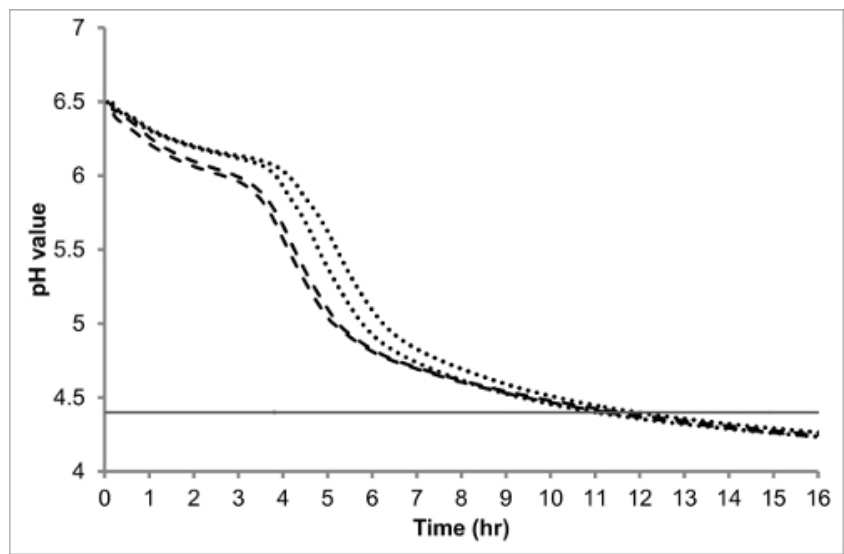

Figure 2. Fermentation profile of the fermented milk (end product) made of semi skimmed milk (1.5\% fat, $3.5 \%$ protein). One liter of milk was inoculated with one $20 \mathrm{~g}$ of fresh starter and fermented at $37^{\circ} \mathrm{C}\left(\cdots \cdot\right.$, duplicate) as well as $45{ }^{\circ} \mathrm{C}(----$, duplicate) for $16 \mathrm{hr}$. The straight line (---) at $\mathrm{pH} 4.4$ is inserted as an indication to determine when the fermentation is completed. Please click here to view a larger version of this figure.

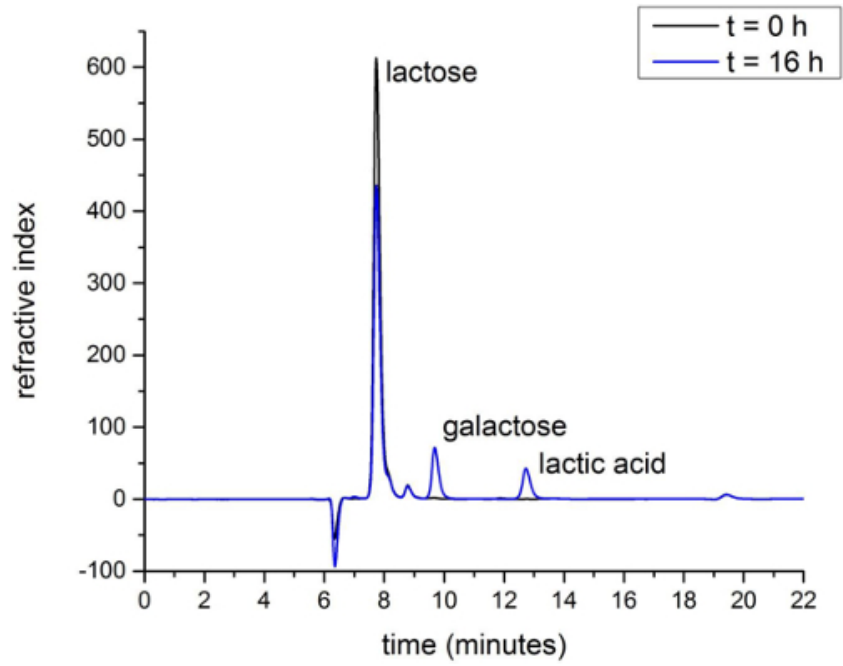

Figure 3. HPLC-elution patterns of non-fermented milk (black) and milk fermented for $\mathbf{1 6} \mathrm{hr}$ with the seed culture (blue). The elution patterns indicate the consumption of lactose and production of galactose and lactate. Sugars and weak acid were identified on the basis of retention time and the peak surface area ratio of UV-absorbance and refractive index. Please click here to view a larger version of this figure. 


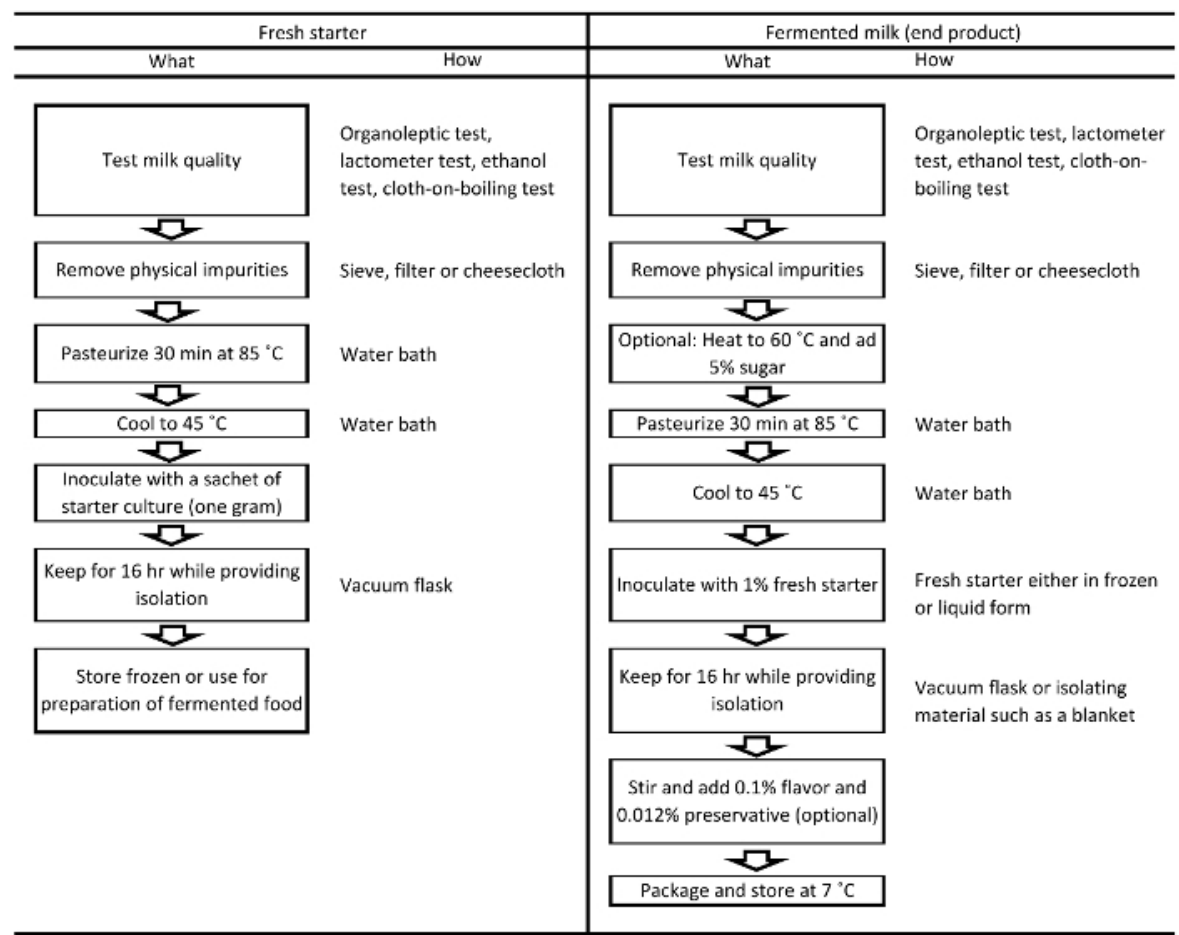

Table 1. Seed culture application protocol. Please click here to view a larger version of this table.

\begin{tabular}{|c|c|c|c|c|c|c|c|c|c|}
\hline \multirow[t]{2}{*}{ Name } & \multirow[t]{2}{*}{ Raw material } & \multicolumn{2}{|l|}{ L. rhamnosus } & \multicolumn{2}{|l|}{ 5. thermophilus } & \multirow[t]{2}{*}{ S. th/L.rha } & \multirow[t]{2}{*}{$t(h)$} & \multirow[t]{2}{*}{$T\left({ }^{\circ} \mathrm{C}\right)$} & \multirow[t]{2}{*}{$\mathrm{pH}$} \\
\hline & & $\operatorname{mean}\left(\mathrm{CFU} \mathrm{\textrm {ml } ^ { - 1 } )}\right.$ ) & SD (CFU $\mathrm{ml}^{-1}$ ) & mean $\left\langle\mathrm{CFU} \mathrm{ml^{-1 } \rangle}\right.$ & SD (CFU mll ${ }^{-1}$ ) & & & & \\
\hline Fresh starter & Imilk & $7.1 \times 10^{\wedge} 7$ & $1.2 \times 10^{\wedge} 7$ & $1.6 \times 10^{\wedge} 8$ & $0.7 \times 10^{\wedge} 8$ & $22 \pm 5$ & 16 & 37 & 4.4 \\
\hline Fresh starter & milk & $3.1 \times 10^{4} 7$ & $0.6 \times 10^{\wedge} 7$ & $6.6 \times 10^{\wedge} 8$ & $2.1 \times 10^{\circ} 8$ & $22 \pm 2$ & 16 & 45 & 4.4 \\
\hline Fermented millk & millk & $6.1 \times 10^{\wedge} 7$ & $0.6 \times 10^{\wedge 7}$ & $2.4 \times 10^{\circ} 9$ & $0.1 \times 10^{\circ} \times 9$ & $39 \pm 3$ & 16 & 37 & 4.3 \\
\hline Fermented millk & milk & $1.7 \times 10^{\wedge} 7$ & $0.1 \times 10^{\times 17}$ & $1.3 \times 10^{\wedge} 9$ & $0.1 \times 10^{\circ} 9$ & $75 \pm 35$ & 16 & 45 & 4.3 \\
\hline Obushera & sorghum, water & $2.1 \times 10^{\wedge} 8$ & $1.0 \times 10^{\wedge} 8$ & ND & - & $\cdot$ & 24 & 25 & 4.1 \\
\hline Zomkom & wheat $(9 \%$ w/w $)$, water $(91 \%$ w/w $)$ & $3.4 \times 10^{\wedge} 8$ & $\cdot$ & $0.3 \times 10^{\wedge} 7$ & - & - & 15 & 37 & $<4,3$ \\
\hline Uji & sorghum and maize (1:1 ratio), water & $3.7 \times 10^{\wedge} 9$ & - & ND & - & - & 16 & 45 & NO \\
\hline Mutandabota & pulp of the baobab fruit and milk & $6.3 \times 10^{\wedge} 8$ & - & ND & - & - & 24 & 30 & 3.5 \\
\hline \begin{tabular}{|l|} 
Kwete \\
\end{tabular} & maize, water & $3.3 \times 10^{\wedge 9}$ & 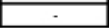 & ND & - & - & 20 & 37 & 4.2 \\
\hline
\end{tabular}

Table 2. Propagation of Lactobacillus rhamnosus yoba 2012 in a variety of fermented Foods. Data were obtained from Kort et al. ${ }^{15}$. Fermentations were carried out at $37^{\circ} \mathrm{C}$ unless stated otherwise. The cell count of $L$. rhamnosus yoba 2012 and S. thermophilus $\mathrm{C} 106$ after

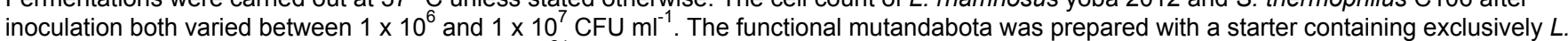
rhamnosus yoba 2012 as reported by Mpofu et al. ${ }^{24}$; ND, not determined. Please click here to view a larger version of this table.

Supplemental File. Local production and sales of probiotic yoghurt in rural Africa. Shots and pictures are taken in Balawoli and Namagera, Uganda, May 2016. The clip shows the value chain starting from milk reception to processing, packaging, sales and finally to the consumption of a batch of $50 \mathrm{~L}$ of probiotic yoghurt, prepared with the use of only basic equipment. Please click here to download.

\section{Discussion}

The simple production protocol using basic equipment and a novel fermented food starter culture described in this article facilitates the production of a high quality probiotic fermented milk at the household level and in rural settings in resource-poor countries. It is critical to pasteurize the milk for a minimum of $30 \mathrm{~min}$ in order to obtain sufficient reduction or elimination of spoilage organisms and potential pathogenic micro-organisms. In addition, adequate heating causes denaturation of whey protein ${ }^{17}$ that will subsequently associate with casein micelles ${ }^{25}$ resulting in formation of cross-linkages in the fermented milk ${ }^{26}$. Consequently, viscosity of the end product is increased compared to less extensively heated milk ${ }^{27}$. It is also critical to avoid inoculation of the milk above $45^{\circ} \mathrm{C}$, because at higher temperatures the bacteria will be inactivated.

Similarly, if available and cost-effective, the use of UHT milk is preferred, especially for the production of the fresh starter. Firstly, UHT milk is virtually free from unwanted micro-organisms. Secondly, in UHT milk whey proteins have been extensively denatured, which makes them more accessible for bacterial proteases, promoting their degradation and subsequent growth of the yogurt bacteria. During the process of cooling down, proteins partially refold to their native state, therefore re-heating prior to inoculation is beneficial for yogurt production. Prolonged fermentation results in a fermented milk with a $\mathrm{pH}<4.4$, which is often undesirable. Fermentation can be stopped in a timely manner by placing the fermented milk in the fridge.

Locally produced yogurts in Africa have been shown to contain significant levels of lactococci ${ }^{28}$ such as $L$. lactis, which can cause the production of peptides that have a bitter flavor ${ }^{29-32}$, which is generally undesirable ${ }^{31}$. Therefore, it is critical that fermentation takes place at an temperature between 45 and $35^{\circ} \mathrm{C}^{15,28}$. Since the temperature will slowly decrease during fermentation in a semi-controlled environment, inoculation is done at $45^{\circ} \mathrm{C}$, the highest temperature allowed. Sufficient isolation during fermentation is essential to avoid decrease of the temperature below $35^{\circ} \mathrm{C}$. 
Manual production of yogurt in rural setting has a relatively high risk of microbial contamination by spoilage organisms. In particular, yeasts are able to propagate under the acidic conditions in yogurt. Yeast contamination can lead to excessive gas production, either in the incubation phase or during storage, thereby spoiling the yogurt immediately or significantly shortening its shelf life ${ }^{33,34}$. Yeast levels can be minimized by heat sterilization and/or cleaning with sodium hypochlorite of all the utensils and equipment before every contact with the milk or yogurt. Especially after yeast spoilage has occurred, severe and extensive sterilization and cleaning is required to eliminate the contamination.

The above outlined risks clearly show that the success of the application of this production protocol in resource poor countries is limited by its manual nature and therewith associated increased spoilage rate. The spoilage rate becomes even higher in communities that lack cooling facilities or have highly fluctuating availability of electricity. Also the lack of access to affordable high-quality packaging material can limit the uptake of the described protocol. The required equipment is basic and universal, but a laboratory or kitchen thermometer is essential. Finally, currently only a limited number of countries have the facilities to produce the freeze dried starter culture. Most resource-poor countries lack those facilities, and therefore depend on import to obtain this product.

Among foodstuffs, fermented milk including yogurt is the most common vehicle for probiotic bacteria. The production of fermented milk does not require special equipment apart from a thermometer. Thus the combination of the above described first generic probiotic starter culture ${ }^{13}$ with a simple production protocol allows for the reproducible, controlled and safe production of probiotic fermented milk by almost anybody at any place, including production at the household and cottage industry levels in rural areas in resource-poor countries. In traditionally practiced natural fermentations, equal levels of probiotic bacteria cannot be guaranteed ${ }^{9}$. The self-stable starter culture in $1 \mathrm{~g}$ sachets enable small-scale producers to cost-effectively produce fermented foods, without the need to buy high amounts of starter cultures that usually lose viability after opening the package, especially when kept at room temperature and at a high relative humidity, which is to our knowledge the case for all other available yogurt starter cultures. Furthermore, the amount of dried bacteria that is imported remains very low, below $0.1 \%$ of the probiotic culture concentration in the final product, because almost all of the starter culture is produced locally due to the pre-incubation method that is described in this protocol.

The production of fermented milk is described in detail in this article and can be a first step to master the art of producing probiotic fermented foods, which subsequently can be applied to ferment many types of other foods (as referred to in this article). To upgrade basic fermented milk, a possible next step is the production of real-fruit fermented milk. This requires the preparation of a sterile fruit preserve (a mixture of fruit, sugar and optionally some additives) or the purchase of a ready-made fruit preserve to be mixed with the fermented milk after fermentation ${ }^{35,36}$.

\section{Disclosures}

Wilbert Sybesma and Remco Kort are the founders of the Yoba for Life foundation, a not-for profit organization, accredited by the Dutch Tax Authorities as a Public Benevolent Institution (PBI), which aims to promote local production and consumption of fermented products in Africa. Fermented products made with the Yoba seed culture, including yogurt, zomkom, obushera and mutandabota are not marketed by the foundation as such, but the Yoba for Life foundation stimulates local production and ownership, allowing income-generating activities for African entrepreneurs in the food sector. The Yoba for Life foundation distributes and sells ready-to-use sachets with dried bacterial seed cultures through a network of partners and volunteers to facilitate the local production of dairy and cereal-based products by controlled bacterial fermentation.

\section{Acknowledgements}

The authors acknowledge the East African Dairy Development (EADD) project for their practical support on the ground in training dairy cooperatives in rural Uganda in fermented milk production. CSK Food Enrichment is acknowledged for production, quality control and assessment of fermentative capacity of the starter culture. Lactosan $\mathrm{GmbH} \&$ Co, Austria, is acknowledged for production assistance. The authors thank Karin Overkamp (TNO Microbiology and Systems Biology, Zeist, The Netherlands) for the HPLC analysis, and Derrick Assimwe (UIRI) for recording author statements in Uganda. These recordings took place during the IDRC-supported inception meeting of the Fermented food for life project (CIFSRF Phase 2) in Entebbe, Uganda, May 2016. The VU University Amsterdam and the Micropia museum are acknowledged for financial contributions and provision of laboratory facilities for the production of the video described in this article. The authors thank Wim van Egmond for microscopy of yoghurt bacteria.

\section{References}

1. Kosek, M., Bern, C., \& Guerrant, R. L. The global burden of diarrhoeal disease, as estimated from studies published between 1992 and 2000. Bull. World Health Organ. 81, 197-204 (2003).

2. Parashar, U. D. et al. Global Mortality Associated with Rotavirus Disease among Children in 2004. J. Infect. Dis. 200, S9-S15 (2009).

3. Szajewska, H., Skòrka, A., Ruszczyński, M., \& Gieruszczak-Białek, D. Meta-analysis: Lactobacillus GG for treating acute diarrhoea in children. Aliment. Pharmacol. Ther. 25, 871-881 (2007).

4. Guandalini, S. Probiotics for Prevention and Treatment of Diarrhea: J. Clin. Gastroenterol. 45, S149-S153 (2011).

5. Guarino, A., Guandalini, S., \& Vecchio, A. L. Probiotics for prevention and treatment of diarrhea. J. Clin. Gastroenterol. 49, S37-S45 (2015).

6. Allen, S. J., Martinez, E. G., Gregorio, G. V., \& Dans, L. F. Probiotics for treating acute infectious diarrhoea. Cochrane Database Syst Rev. 11, (2010).

7. De Roos, N. M., \& Katan, M. B. Effects of probiotic bacteria on diarrhea, lipid metabolism, and carcinogenesis: a review of papers published between 1988 and 1998. Am. J. Clin. Nutr. 71, 405-411 (2000).

8. Sybesma, W., Kort, R., \& Lee, Y.-K. Locally sourced probiotics, the next opportunity for developing countries? Trends Biotechnol. 33, 197-200 (2015).

9. Franz, C. M. A. P. et al. African fermented foods and probiotics. Int. J. Food Microbiol. 190, 84-96 (2014). 
10. Reid, G. et al. Harnessing microbiome and probiotic research in sub-Saharan Africa: recommendations from an African workshop. Microbiome 2, 12 (2014).

11. Holzapfel, W. H. Appropriate starter culture technologies for small-scale fermentation in developing countries. Int. J. Food Microbiol. 75, 197-212 (2002).

12. Monachese, M. et al. Probiotics and prebiotics to combat enteric infections and HIV in the developing world: a consensus report. Gut Microbes 2, 198-207 (2011).

13. Kort, R., \& Sybesma, W. Probiotics for every body. Trends Biotechnol. 30, 613-615 (2012).

14. Gorbach, S. L., \& Goldin, B. R. Lactobacillus acidophilus strains of bacteria and compositions thereof. EP0199535. (1986).

15. Kort, R. et al. A novel consortium of Lactobacillus rhamnosus and Streptococcus thermophilus for increased access to functional fermented foods. Microbial Cell Factories (2015).

16. Douglas Goff, H. in Dairy Science and Technology Education Series. University of Guelph, Food Science, (2015).

17. Tribby, D. in The Sensory Evaluation of Dairy Products. (eds. Clark, S., Costello, M., Drake, M., \& Bodyfelt, F.) 191-223 Springer US, (2008).

18. Odunfa, S. A. African fermented foods: from art to science. MIRCEN J. Appl. Microbiol. Biotechnol. 4, $259-273$ (1988).

19. Nout, M. J. R., \& Sarkar, P. K. in Lactic Acid Bacteria: Genetics, Metabolism and Applications. (eds. Konings, W. N., Kuipers, O. P., \& Veld, J. H. J. H. I. 't) 395-401 Springer Netherlands, (1999).

20. Harrison, P. M. B. D. T., \& Tomkins, A. M. Fermented cereal gruels: Towards a solution of the weanling's dilemma. Food Nutr. Bull. 13 (1991).

21. Narvhus, J. A., \& Gadaga, T. H. The role of interaction between yeasts and lactic acid bacteria in African fermented milks: a review. Int. J. Food Microbiol. 86, 51-60 (2003).

22. Mukisa, I. M. et al. The dominant microbial community associated with fermentation of Obushera (sorghum and millet beverages) determined by culture-dependent and culture-independent methods. Int. J. Food Microbiol. 160, 1-10 (2012).

23. Christèle, I.-V. et al. Traditional recipes of millet-, sorghum-and maize-based dishes and related sauces frequently consumed by young children in Burkina Faso and Benin. (2010).

24. Mpofu, A. et al. Development of a locally sustainable functional food based on mutandabota, a traditional food in southern Africa. J. Dairy Sci. 97, 2591-2599 (2014).

25. Lucey, J. A., \& Singh, H. Formation and physical properties of acid milk gels: a review. Food Res. Int. 30, 529-542 (1997).

26. Lucey, J. A. Formation and Physical Properties of Milk Protein Gels. J. Dairy Sci. 85, 281-294 (2002).

27. Lucey, J. A. Cultured dairy products: an overview of their gelation and texture properties. Int. J. Dairy Technol. 57, 77-84 (2004).

28. Mukisa, I.M., \& Kyoshabire, R. Microbiological, physico-chemical and sensorial quality of small-scale produced stirred yoghurt on the market in Kampala city, Uganda. Nutr. Food Sci. 40, 409-418 (2010).

29. Omaea, M., Maeyama, Y., \& Nishimura, T. Sensory Properties and Taste Compounds of Fermented Milk Produced by Lactococcus lactis and Streptococcus thermophilus. Food Sci. Technol. Res. 14, 183-189. (2008).

30. Bockelmann, W., Kiefer, B., Geis, A., \& Teuber, M. in Milk Proteins. 225-227 Springer, (1989).

31. Tamime, A. Y., \& Robinson, R. K. Tamime and Robinson's yoghurt: science and technology. Elsevier, (2007).

32. Tamime, A. Y., \& Deeth, H. C. Yogurt: Technology and Biochemistry. (1980).

33. Fleet, G. Spoilage Yeasts. Crit. Rev. Biotechnol. 12, 1-44 (1992).

34. Viljoen, B. C., Lourens-Hattingh, A., Ikalafeng, B., \& Peter, G. Temperature abuse initiating yeast growth in yoghurt. Food Res. Int. 36, 193-197 (2003).

35. Baker, D. B., \& Hulett, V. Low fat thin-bodied yogurt product and method. Google Patents, (1989).

36. Bamforth, C. W., \& Ward, R. E. in The Oxford Handbook of Food Fermentations. 385 (2014). 